\title{
High precision analysis of isotopic composition for samples used for nuclear cross-section measurements
}

\author{
Yuji Shibahara ${ }^{1, \text { a }}$ Jun-ichi Hori ${ }^{1}$, Koichi Takamiya ${ }^{1}$, Toshiyuki Fujii ${ }^{1}$, Satoshi Fukutani ${ }^{1}$, Tadafumi Sano ${ }^{1}$, \\ and Hideo Harada ${ }^{2}$ \\ 1 Kyoto University, Research Reactor Institute, 590-0494, Kumatori-cho, Sennan-gun, Osaka, Japan \\ 2 Japan Atomic Energy Agency, Nuclear Science and Engineering Center, 319-1195, Tokai-mura, Naka-gun, Ibaraki, Japan
}

\begin{abstract}
For the accuracy improvement of nuclear data of minor actinides and long-lived fission products in the project of "Research and development for Accuracy Improvement of neutron nuclear data on Minor Actinides", the isotopic compositions of two Am samples $\left({ }^{241} \mathrm{Am}\right.$ sample and ${ }^{243} \mathrm{Am}$ sample) were analyzed by thermal ionization mass spectrometry. Only the peak of ${ }^{241} \mathrm{Am}$ was observed in the analysis of ${ }^{241} \mathrm{Am}$ sample, and level of isotopic impurities were improved from $0.1 \%$ to $0.0004 \%$. In the analysis of ${ }^{243} \mathrm{Am}$ sample, the peak of unreported isotope of ${ }^{242 m} \mathrm{Am}$ was observed in addition to the peaks of ${ }^{243} \mathrm{Am}$ and ${ }^{241} \mathrm{Am}$. The mass spectrometry also showed that ${ }^{243} \mathrm{Am}$ sample has other unreported impurities such as ${ }^{239} \mathrm{Pu}$ and ${ }^{240} \mathrm{Pu}$.
\end{abstract}

\section{Introduction}

For the development of innovative nuclear fuel system and nuclear transmutation system, the accuracy improvements of neutron nuclear data for minor actinides (MAs) and long-lived fission products (LLFPs) are indispensable. The accelerator neutron-nucleus reaction measurement instrument (ANNRI) was installed at the Japan proton accelerator research complex (J-PARC) to obtain the high accuracy neutron nuclear data [1-4].

A nuclear data project entitled as "research and development for Accuracy Improvement of neutron nuclear data on Minor ACtinides (AIMAC)" was launched at 2013 as one of the "Innovative Nuclear Research and Development Program" [5]. This project consists of four research field groups such as differential nuclear data measurement, integral nuclear data measurement, nuclear chemistry, and nuclear data evaluation. The objective of our group is to obtain the high quality isotopic composition data of samples contributing to the evaluation of nuclear cross-section measurement data by mass spectrometry etc.

We focused on ${ }^{241,243} \mathrm{Am}$ targets in our project. Their neutron nuclear data measurements and evaluations are in progress. In this study, we analyzed the isotopic composition of two Am samples (main component was ${ }^{241} \mathrm{Am}$ and ${ }^{243} \mathrm{Am}$ respectively) currently evaluating the neutron nuclear data by the thermal ionization mass spectrometry. Because there is no suitable standard reference material for the analysis of isotopic composition of Am, the analysis of isotopic composition of $U$ was conducted as the performance check of the Am sample analysis. The isotopic compositions of Am samples were analyzed according to the result of the analysis of $U$.

\section{Experimental}

\section{Samples of ${ }^{241} \mathrm{Am}$ and ${ }^{243} \mathrm{Am}$}

Am samples of ${ }^{241} \mathrm{Am}$ and ${ }^{243} \mathrm{Am}$ were purchased from JSC Khlopin Radium Institute Russia and were used without further purification. The profiles of these samples such as the isotopic composition and the chemical composition were summarized in Table 1.

\section{Analysis by TIMS}

The isotopic composition of Am samples and $U$ were analysed with a thermal ionization mass spectrometer (TRITON-T1 $^{\text {TM }}$, Thermo Fisher Scientific) with a rhenium double filament system [6]. To reduce the degree of the radioactive contamination with $\alpha$-emitter, the loading amount was $c a .1 \mathrm{ng}$, and a secondary electron multiplier detector (SEM) was used as a detector.

\section{TIMS analysis of $U$}

The CRM U010 standard material, which is the enriched U consisting of $1 \%$ of ${ }^{235} \mathrm{U}$ [7], was used for the analysis of isotopic composition of $\mathrm{U}$. About $1 \mu \mathrm{L}$ of $\mathrm{U}$ in $1 \mathrm{M} \mathrm{HNO}_{3}$ solution $\left(1 \times 10^{-1} \mathrm{ppb}\right.$ to $\left.5 \mathrm{ppm}\right)$ was loaded on a rhenium evaporation filament: the loading amount was ranged from $100 \mathrm{fg}$ to $5 \mathrm{ng}$. Because of the total amount of U loaded on the filament, the mass spectrometry was conducted with a SEM and the peak jump method based on our previous study of $\mathrm{U}$ and $\mathrm{Pu}[8,9]$.

A rhenium ionization filament was heated until the ion current of ${ }^{187} \mathrm{Re}$ became $5 \times 10^{-13} \mathrm{~A}$. After maximizing the ${ }^{187} \mathrm{Re}$ ion current by optimizing ion lens system the ion current of ${ }^{187} \mathrm{Re}$ was adjusted to be $5 \times 10^{-13} \mathrm{~A}$ again. The evaporation filament was then heated gradually until the current of the $U$ ion beam showed the enough for the isotopic composition analysis $\left(\mathrm{ca} .3 \times 10^{-14} \mathrm{~A}\right.$, in the case

\footnotetext{
a e-mail: y-shibahara@rri.kyoto-u.ac.jp
} 
Table 1. Profiles of samples of ${ }^{241} \mathrm{Am}$ and ${ }^{243} \mathrm{Am}$.

\begin{tabular}{|c|c|c|}
\hline & ${ }^{241} \mathrm{Am}$ sample & ${ }^{243} \mathrm{Am}$ sample \\
\hline $\begin{array}{l}\text { Concentration of } \\
\text { radioactivity Activity } \\
\text { measurement error } \\
(\mathrm{P}=0.95)\end{array}$ & $132.78 \mathrm{kBq} / \mathrm{mL}$ & $9.98 \mathrm{kBq} / \mathrm{mL}$ \\
\hline $\begin{array}{l}\text { Radioactivity impurities } \\
\text { (for }{ }^{241} \mathrm{Am} \text { )/ } \\
\text { Radionuclide } \\
\text { components by } \alpha- \\
\text { spectrometry (for }{ }^{243} \mathrm{Am} \text { ) }\end{array}$ & No more than $0.3 \%$ & $\begin{array}{l}{ }^{241} \mathrm{Am}: 16.99 \% \\
{ }^{243} \mathrm{Am}: 38.32 \% \\
{ }^{244} \mathrm{Cm}: 43.99 \% \\
{ }^{242} \mathrm{Cm}: 0.7 \%\end{array}$ \\
\hline Isotopic composition & ${ }^{241} \mathrm{Am}: 99.9 \%$ & $\begin{array}{l}{ }^{243} \mathrm{Am}: 97.3 \% \\
{ }^{241} \mathrm{Am}: 2.7 \%\end{array}$ \\
\hline Chemical composition & $\begin{array}{l}\text { Am: } 99.9 \% \\
\text { Pu: } 0.09 \% \\
\text { Np: } 0.01 \%\end{array}$ & $\begin{array}{c}\text { Am. } 99.58 \% \\
\text { Fe, Ca, Na: } 0.07 \% \\
\text { B: } 0.09 \% \\
\text { Gd: } 0.03 \% \\
\text { etc. }\end{array}$ \\
\hline
\end{tabular}

of $1 \mathrm{ng} \mathrm{U}$ loaded on the filament). After the optimization of the ion lens system with the ion beam of ${ }^{238} \mathrm{U}$ and the confirmation of the stability of the ion beam of $U$, the isotopic composition of $U$ were analyzed. The vacuum during data acquisitions was better than $5 \times 10^{-6} \mathrm{~Pa}$ in the ion source. The ion beam intensity of each $U$ isotope was integrated for $4 \mathrm{~s}$, and the isotopic compositions were evaluated from the isotopic ratios of ${ }^{234} \mathrm{U} /{ }^{238} \mathrm{U},{ }^{235} \mathrm{U} /{ }^{238} \mathrm{U}$ and ${ }^{236} \mathrm{U} /{ }^{238} \mathrm{U}$.

\section{TIMS analysis of Am}

About $1.5 \mathrm{ng}$ of Am samples $\left({ }^{241} \mathrm{Am}\right.$ sample: $1.6 \mathrm{ng},{ }^{243} \mathrm{Am}$ sample: $1.4 \mathrm{ng}$, respectively) were loaded on a rhenium evaporation filament. Because of the difference in the ionization potential of $\mathrm{Am}(5.97 \mathrm{eV})$ and $\mathrm{U}(6.19 \mathrm{eV})$ [10], the ${ }^{187} \operatorname{Re}$ ion current of a rhenium ionization filament was lower than that of the $\mathrm{U}$ case $\left(c a .3 .5 \times 10^{-13} \mathrm{~A}\right)$. After adjusting the ion current of ${ }^{187} \mathrm{Re}$ by heating the ionization filament and the optimizing of ion lens system, a rhenium evaporation filament was heated gradually until the Am ion beam showed the enough intensity. After the optimization of the ion lens system with the ion beam of Am $\left({ }^{241} \mathrm{Am}\right.$ beam for ${ }^{241} \mathrm{Am}$ sample, and ${ }^{243} \mathrm{Am}$ beam for ${ }^{243}$ Am sample) and the confirmation of the stability of the ion beam of Am, the isotopic compositions of Am samples were analyzed. The ion beam intensity of each Am isotope was integrated for $4 \mathrm{~s}$, and the isotopic compositions were evaluated from the isotopic ratios of ${ }^{243} \mathrm{Am} /{ }^{241} \mathrm{Am}$ for ${ }^{241} \mathrm{Am}$ sample and that of ${ }^{241} \mathrm{Am} /{ }^{243} \mathrm{Am}$ for ${ }^{243} \mathrm{Am}$ sample, respectively.

\section{Results and discussion}

\section{TIMS analysis of $U$}

The mass spectrum of CRM U010 [7] obtained in this study and the dependency of the analytical error in ${ }^{235} \mathrm{U} /{ }^{238} \mathrm{U}$ ratio measurement on the loading amount of $\mathrm{U}$ are shown in Figs. 1 and 2. In the case of loading amount of $\mathrm{U}$ was over $1 \mathrm{ng}$, the isotopic abundance of ${ }^{235} \mathrm{U} /{ }^{238} \mathrm{U}$ showing $\mathrm{ca}$. $1 \%$ would be analyzed with the accuracy of $1 \%$ in 2 SD. Table 2 show the comparison of $U$ isotopic composition between the certified values and the analytical

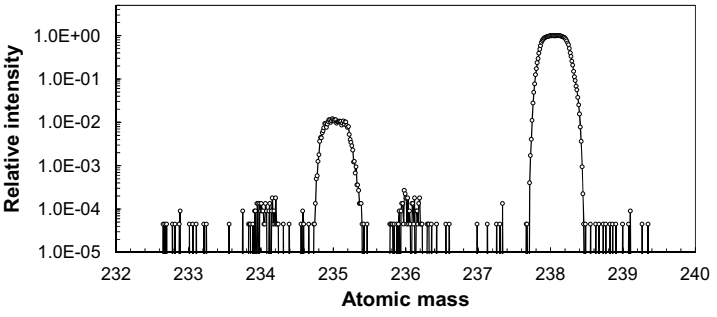

Figure 1. Mass spectrum of U010 (loading amount: 1 ng).

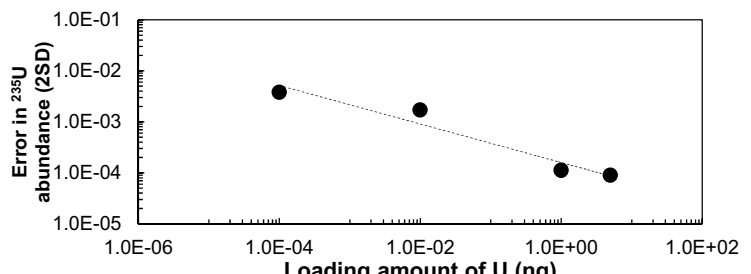

Figure 2. Error in ${ }^{235} \mathrm{U}$ abundance measurement as a function of loading amount of $\mathrm{U}$.

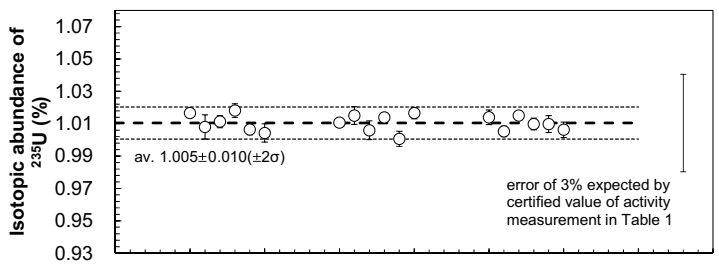

Figure 3. Reproducibility of ${ }^{235} \mathrm{U}$ isotope analysis.

Table 2. Comparison of U isotopic composition.

\begin{tabular}{lll}
\hline & \multicolumn{2}{c}{ Isotopic abundance (\%) } \\
& Certified value [7] & Analytical result $n=3$ \\
\hline $\mathrm{U}-234$ & $0.00541(5)$ & $0.006(1)$ \\
$\mathrm{U}-235$ & $1.0037(10)$ & $1.005(11)$ \\
$\mathrm{U}-236$ & $0.00681(7)$ & $0.007(1)$ \\
$\mathrm{U}-238$ & $98.984(1)$ & $98.982(11)$ \\
\hline
\end{tabular}

Parentheses means error in $\pm 2 \sigma$.

result in this study. The analytical result of the loading amount of $1 \mathrm{ng}$ showed the agreement within the error with the certified values, which were analyzed with the loading amount of several $100 \mathrm{ng}$ in general [7]. By the comparison between the analytical result in this study and the error in the activity measurement reported as the certified value in Table 1, the TIMS analysis of loading amount of several ng would provide the improved isotopic composition data of Am samples (especially, ${ }^{243}$ Am sample) as shown in Fig. 3.

\section{TIMS analyses of Am samples}

The mass spectrum of ${ }^{241} \mathrm{Am}$ sample is shown in Fig. 4, showing that other isotopes of Am were under background level. Table 3 shows the result of three time analyses of ${ }^{241} \mathrm{Am}$ sample. The isotopic abundance of ${ }^{241} \mathrm{Am}$ in ${ }^{241} \mathrm{Am}$ sample would be expected as over $99.9996 \%$, and the other isotopes would be less than $0.0004 \%$ : these were evaluated with the $\mathrm{S} / \mathrm{N}$ ratio of the ${ }^{241} \mathrm{Am}$ peak of $\mathrm{ca} .2 \times 10^{5}$. This value shows the improvement of the isotopic abundance of ${ }^{241} \mathrm{Am}$ sample in double digits by TIMS measurement.

In the analysis of ${ }^{243} \mathrm{Am}$ sample, the mass spectrum as shown in Fig. 5 was obtained. The ${ }^{243} \mathrm{Am}$ sample shows the peak at the atomic mass of 242 in addition to the peaks 


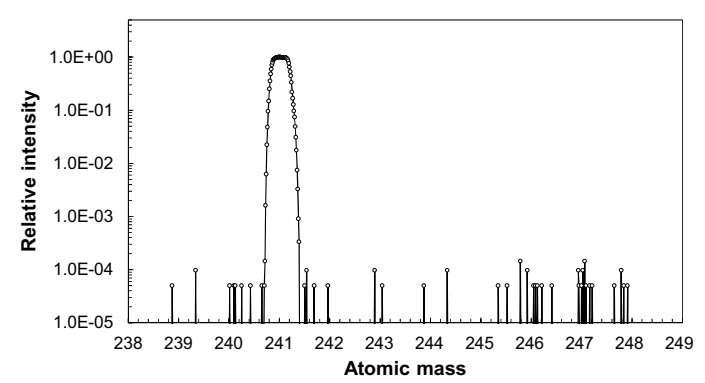

Figure 4. Mass spectrum of ${ }^{241} \mathrm{Am}$ sample.

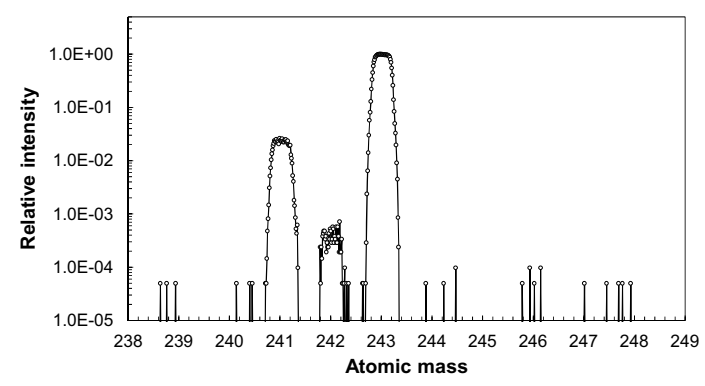

Figure 5. Mass spectrum of ${ }^{243} \mathrm{Am}$ sample.

Table 3. Analytical result of ${ }^{241} \mathrm{Am}$ sample.

\begin{tabular}{lll}
\hline & ${ }^{241} \mathrm{Am}$ & other \\
\hline Run-1 & $>99.9995 \%$ & $<0.0005 \%$ \\
Run-2 & $>99.9997 \%$ & $<0.0003 \%$ \\
Run-3 & $>99.9998 \%$ & $<0.0002 \%$ \\
\hline
\end{tabular}

Table 4. Analytical result of ${ }^{243} \mathrm{Am}$ sample.

\begin{tabular}{lll}
\hline & ${ }^{243} \mathrm{Am}$ & ${ }^{241} \mathrm{Am}$ \\
\hline Run-1 & $97.71(3) \%$ & $2.29(3) \%$ \\
Run-2 & $97.72(3) \%$ & $2.28(3) \%$ \\
Run-3 & $97.71(5) \%$ & $2.29(5) \%$ \\
\hline \multicolumn{3}{l}{ Parentheses means error in $\pm 2 \sigma}$.
\end{tabular}

of the reported isotopes of ${ }^{243} \mathrm{Am}$ and ${ }^{241} \mathrm{Am}$ in Table 1. The isobaric interference would be expected as the reason of the peak at the atomic mass of 242 in general. The interference by the isobar was rejected, since (1) there were no accompanied peaks of other element interfering to the mass spectrum of ${ }^{243} \mathrm{Am}$ sample such as $\mathrm{Pu}$ and $\mathrm{Cm}$, and (2) the intensity of the peak at atomic mass of 242 was not changed during the heat up of filament (as shown in Fig. 7). This means that the peak at the atomic mass of 242 would be expected as the peak of ${ }^{242 \mathrm{~m}} \mathrm{Am}$, the existence of ${ }^{242 \mathrm{~m}} \mathrm{Am}$ was not reported in the warrantied card as shown in Table 1.

The results of the three times analysis of ${ }^{243}$ Am sample were summarized in Table 4 . The abundances of ${ }^{243} \mathrm{Am}$ and ${ }^{241} \mathrm{Am}$ were evaluated as $97.7 \%$ and $2.3 \%$ as shown in Table 4 . These values show the difference in $0.4 \%$ from the certified values in Table 1. Because this mismatch between the certified value and the analytical result could become a reason of unexpected uncertainty, the identification of the cause of this mismatch would become more important. The unreported isotope of ${ }^{242 \mathrm{~m}} \mathrm{Am}$ was evaluated as the isotopic ratio of ${ }^{242 \mathrm{~m}} \mathrm{Am} /{ }^{243} \mathrm{Am}: 0.039 \pm 0.006 \%$.

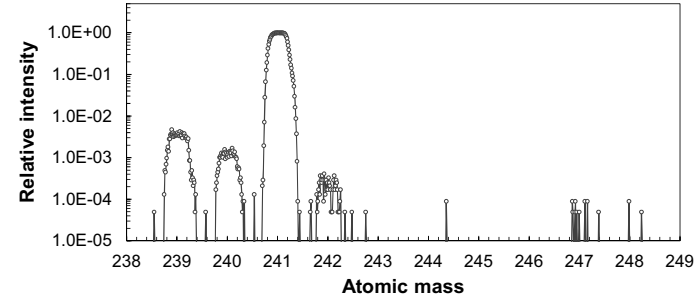

Figure 6. Peaks of impurities observed in heat up process of ${ }^{241} \mathrm{Am}$ sample. The filament current was lower than that of Fig. 4.

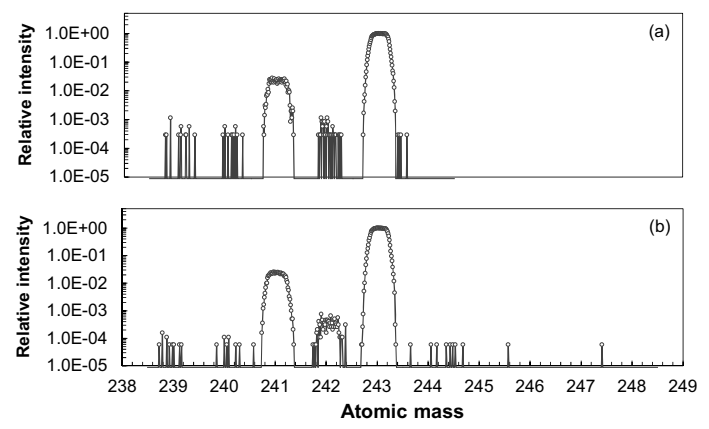

Figure 7. Peaks of impurities observed in heat up process of ${ }^{243} \mathrm{Am}$ sample. The filament current of (b) was higher than that of (a), but lower than tat of Fig. 5.

\section{Impurities observed in heating up process}

During the heating up of the evaporation filament of the ${ }^{241} \mathrm{Am}$ sample, the ion beams at atomic masses of 239 , 240 and 242 was observed as shown in Fig. 6. These peaks would be caused by the existence of $\mathrm{Pu}$ as shown in Table 1 . The ${ }^{243} \mathrm{Am}$ sample also shows the possibility of the existence of $\mathrm{Pu}$, which was not reported in this sample, as shown in Fig. 7. Figure 7(a) shows that the peak intensity at the atomic mass of 239 and 240 would be equal to that of ${ }^{242 \mathrm{~m}} \mathrm{Am}$, suggesting that ${ }^{243} \mathrm{Am}$ sample might contain at least several $0.01 \%$ of Pu. Because of (1) the difference in the ionization potential between Am $(5.97 \mathrm{eV})$ and $\mathrm{Pu}(6.02 \mathrm{eV})$ [10] and (2) the difference in the timing for obtaining the mass spectra of Fig. 6 and Fig. 7, the quantitative evaluation of $\mathrm{Pu}$ is hard from this spectrum. The existence of $\mathrm{Pu}$ would become the factor of uncertainty of the neutron nuclear cross-section data, meaning that the consideration of the method of quantitative analysis of $\mathrm{Pu}$ such as the isotopic spike technique [6] will be important as the further study.

\section{Conclusions}

The isotopic compositions of two Am samples $\left({ }^{241} \mathrm{Am}\right.$ sample and ${ }^{243} \mathrm{Am}$ sample) used for nuclear cross-section measurements in AIMAC project were analyzed by TIMS. It was observed that the ${ }^{241} \mathrm{Am}$ sample consisted almost entirely of ${ }^{241} \mathrm{Am}$. The significant figure of isotopic purity of ${ }^{241} \mathrm{Am}$ sample was improved. The analysis of the isotopic composition of ${ }^{243} \mathrm{Am}$ sample showed that the isotopic compositions of ${ }^{243} \mathrm{Am}$ and ${ }^{241} \mathrm{Am}$ were different in $0.4 \%$ compared with the certified value. In the analysis of ${ }^{243} \mathrm{Am}$ sample by TIMS, the unreported impurities such as ${ }^{242 \mathrm{~m}} \mathrm{Am},{ }^{239} \mathrm{Pu}$ and ${ }^{240} \mathrm{Pu}$ were also observed. It was confirmed that TIMS would provide the useful information contributing to the analysis of nuclear crosssection measurement data. 
Present study includes the result of "Research and Development for accuracy improvement of neutron nuclear data on minor actinides" entrusted to the Japan Atomic Energy Agency by the Ministry of Education, Culture, Sports, Science and Technology of Japan (MEXT).

\section{References}

[1] Y. Kiyanagi, K. Kino, M. Furusaka, et al., J. Korean Phys. Soc. 59, 1781 (2011)

[2] A. Kimura, T. Fujii, S. Fukutani et al., J. Nucl. Sci. Technol. 49, 708 (2012)

[3] K. Hirose, K. Furutaka, K.Y. Hara et al., J. Nucl. Sci. Technol. 50, 188 (2013)
[4] T. Fujii, J. Hori, M. Du et al., J. Radioanal. Nucl. Chem. 307, 1945 (2016)

[5] H. Harada, O. Iwamoto, N. Iwamoto et al., EPJ Web of Conferences 93, 06001 (2015)

[6] I.T. Platzner Modern Isotope Ratio Mass Spectrometry, Willey, Chichester (1997)

[7] S. Richter, S.A. Goldberg, Int. J. Mass Spectrom. 229, 181 (2003)

[8] Y. Shibahara, T. Kubota, T. Fujii et al., J. Nucl. Sci. Technol. 303, 1421 (2015)

[9] Y. Shibahara, T. Kubota, T. Fujii et al., J. Radioanal. Nucl. Chem. 307, 2281 (2016)

[10] R.L. David, CRC Handbook of Chemistry and Physics, 84th Edition. CRC Press. Boca Raton, Florida (2003) 